\title{
A Review of Electromyography Signal Analysis Techniques for Musculoskeletal Disorders
}

\author{
T. N. S. Tengku Zawawi ${ }^{1}$, A. R. Abdullah ${ }^{2}$, M.H. Jopri ${ }^{3}$, T. Sutikno ${ }^{4}$, N.M. Saad ${ }^{5}$, R. Sudirman ${ }^{6}$ \\ $1,2,3$ Center for Robotics \& Industrial Automation, Faculty of Electrical Engineering, Universiti Teknikal Malaysia \\ Melaka, Hang Tuah Jaya, 76100 Durian Tunggal, Melaka, Malaysia \\ ${ }^{4}$ Department of Electrical Engineering, Universitas Ahmad Dahlan (UAD), Yogyakarta, Indonesia \\ ${ }^{5}$ Faculty of Electronic \& Computer Engineering, Universiti Teknikal Malaysia Melaka (UTeM), Melaka, Malaysia \\ ${ }^{6}$ Faculty of Electrical Engineering, Universiti Teknologi Malaysia (UTM), Johor Bahru, Malaysia
}

\section{Article Info}

Article history:

Received May 29, 2018

Revised Jun 20, 2018

Accepted Jun 30, 2018

\section{Keywords:}

Electromyography

Musculoskeletal Disorder

Signal Processing

Time domain

Frequency domain

Time-frequency domain

\begin{abstract}
A Social Security Organisation (SOCSO) Malaysia has reported that the incidence of work related to musculoskeletal disorders (MSDs) has been growing planetary in the manufacturing industry. MSDs are the result of repetitive, forceful or awkward movements on our body and or body parts of bones, joints, ligaments and other soft tissues. Workplace pains and strains can be serious and disabling for workers, causing pain and suffering ranging from discomfort to severe disability. To overcome this problem, electromyography is proper to use in Health Screening Program (HSP) it to monitor darn diagnose the muscle's performance for their patient and know the exact localization of muscle pain. The previous researchers has been explore of several in EMG analysis techniques and features proposed in time, frequency and time-frequency domain analysis. This review of common EMG signal processing techniques is proposed by assembling from simple to complex analysis techniques to give the overview information for the other researcher. This is because; the suitable selection of a method and its features settings will ensure readability of the time-frequency representations and reliability of results. The strongest correspond with time-frequency characteristic and resolution also reducing cross term for bilinear will consider it as the optimal method.
\end{abstract}

Copyright $@ 2018$ Institute of Advanced Engineering and Science. All rights reserved.

\section{Corresponding Author:}

A. R. Abdullah,

Center for Robotics \& Industrial Automation, Faculty of Electrical Engineering,

Universiti Teknikal Malaysia Melaka,

Hang Tuah Jaya, 76100 Durian Tunggal, Melaka, Malaysia.

Email: abdulr@utem.edu.my

\section{INTRODUCTION}

\subsection{Musculoskeletal Disorders (MSDs)}

Musculoskeletal Disorders (MSDs) are widespread in the world and as the second most common cause of disability in the work setting and able to give an impact on fatigue and the productivity of the workers [1]. MSDs is involving the injuries and sicknesses that will be affected the human body's movement or musculoskeletal system as muscles, tendons, ligament, nerves, discs, blood vessel and others [2], [3]. Workplace pains and strains can be serious and disabling for workers, causing pain and suffering ranging from discomfort to severe disability because of MSDs problems [4], [5]. All of these disorders are responsible for $40-50 \%$ of the costs of all work- related diseases. Additionally, $50 \%$ of all the absences more than three days are coming from work and $49 \%$ of absences more than two weeks are caused by MSDs [6]. The impact of MSDs can be complicated and give bad effect, and overall health recovery may take a long time, extending beyond the treatment and rehabilitation phase [2]. The new term work-related 
musculoskeletal disorder has fewer etiological implications where it's affecting the back, lower limbs, and especially upper limbs and neck, can be extremely costly if not addressed appropriately [1]. It is important to prevent the MSDs lower or upper limbs that would give direct and indirect effect for the individual and also productive for the company. There is a strong link between exposure to the work-related risk factors for MSD and the development of these disorders.

However, these injuries can be prevented by taking appropriate steps to eliminate or reduce the exposure to the work-related risk factors that can minimize the risk of MSDs in the workplace and then the prevention can be simple and inexpensive by often making straightforward and basic changes can reduce MSD risks significantly [7]. Social Security Organisation (SOCSO) has classified occupational diseases into hearing impairment, musculoskeletal disorder, vibration disorder, skin diseases and occupational asthma [2], [8], [9]. Statistic of industrial accidents in Malaysia recorded 57,639 cases compared to 55,186 for the previous year. Musculoskeletal disorder is one of the critical occupational injuries and disabilities. In 2006, it showed an increment of $174 \%$ from 31 to 85 cases [10]. The effect of MSDs can be progressed from mild to severe disorder [10], [11]. There has been an increasing effort in recent years to investigate the causes of MSDs and to take action to prevent them. In order to prevent low back disorders we must first understand the concept and method that able to detect the symptoms that will contribute to MSDs problem. This literature review provides new insight on the critical literature and issues that have contributed to the results of previous research to being used as the guidance for the future researcher.

These are some working related MSDs by various researches done in previous years on postures/ task performed and type of analysis of MSDs. It is summarized in Table 1.

Table 1. Postures/tasks and MSDs analysis

\begin{tabular}{|c|c|c|}
\hline References & Postures/Task & MSDs analysis \\
\hline Starovoytova. D [7] & $\begin{array}{l}\text { Awkward postures in construction activities } \\
\text { (working overhead, kneeling, back bending } \\
\text { forward, squatting, neck bending, reaching) }\end{array}$ & $\begin{array}{l}\text { Machine-operators' Posture via Rapid- } \\
\text { Upper-Limb-Assessment (RULA) }\end{array}$ \\
\hline Zurada et al. [12] & Low Back Disorders (manual handling) & $\begin{array}{l}\text { Logistic regression (LR), neural networks } \\
\text { (NN), } \\
\text { k-nearest neighbor }(\mathrm{kNN}) \text {, decision trees } \\
\text { (DT), and random forest (RF) }\end{array}$ \\
\hline S.K.Das et al, [13] & $\begin{array}{l}\text { Medical Practitioners (low back, neck, ankle/feet, } \\
\text { knees, upper back, shoulders, wrist/hands) }\end{array}$ & $\begin{array}{c}\text { Body composition measured by } \\
\text { bioelectrical impedance, Waist-Hip Ratio } \\
\text { (WHR) }\end{array}$ \\
\hline Hashim et al, [14] & $\begin{array}{c}\text { Awkward posture among workers in aerospace } \\
\text { industry (push-pull) }\end{array}$ & Rapid-Upper-Limb-Assessment (RULA) \\
\hline Ghosh et al, [15] & $\begin{array}{l}\text { Work related musculoskeletal disorders and back } \\
\text { muscle fatigue among the goldsmiths of India } \\
\text { (Nech, Low Back, Wrist, Shoulder }\end{array}$ & Rapid-Upper-Limb-Assessment (RULA) \\
\hline Nurhayati et al, [16] & $\begin{array}{c}\text { Upper Limb and Lower Back Muscle Activity } \\
\text { During Prolonged Sitting }\end{array}$ & $\begin{array}{c}\text { Maximum Voluntary Contraction (MVC), } \\
\text { Statistical Analysis, Independent Samples } \\
\text { T-Test }\end{array}$ \\
\hline Nur et al, [17] & $\begin{array}{l}\text { Upper limb and lower back muscle activities } \\
\text { (right and left Levator Scapulae, Upper } \\
\text { Trapezius, Anterior Deltoid and Erector Spinae) }\end{array}$ & $\begin{array}{c}\text { Maximum Voluntary Contraction (MVC), } \\
\text { Independent Samples T-Test }\end{array}$ \\
\hline Shair et al, [18] & Upper limb disorders (ULDs), Manual Lifting & $\begin{array}{l}\text { Time Distribution (TD), Frequency } \\
\text { Distribution (FD), Time-Frequency } \\
\text { Distribution (TFD), Linear TFD (Short- } \\
\text { Time Fourier Transform (STFT), Wavelet } \\
\text { Transform (WT), S-Transform), Bilinear } \\
\text { TFD (Wigner-Ville Distribution (WVD), } \\
\text { Choi-William Distribution (CWD) }\end{array}$ \\
\hline Rafie et al, [19] & $\begin{array}{c}\text { Upper Extremity Musculoskeletal Disorders in } \\
\text { Dentists }\end{array}$ & Rapid-Upper-Limb-Assessment (RULA) \\
\hline
\end{tabular}




\subsection{Electromyography Signal}

The measurement of muscle signal from electromyography (EMG) is able to assist SOCSO in diagnose MSDs problem from earlier. Electromyography (EMG) is the analytical study of electrical activity produced by skeletal muscles [20]. It will measure the electrical potential between the surface skins to muscle contraction that represent neuromuscular activities and easier to use in research on physiology. EMG signal can be captured by two types of electrodes which are surface (non-invasive) and intramuscular fine wire (invasive) [18], [21]. Intramuscular fine wire is used to record EMG signal from deep muscle, however, is requires needle insertion into the muscle that need clinical assistant and cause pain to the subject. On the contrary, surface EMG electrode is easy to apply and free from pain [21]. EMG signal is described by its amplitude and frequency. The signals are complicated and non-stationary signal with highly complex time and frequency characteristics [21]. The amplitude of EMG signal is normally in the range of 0-10 millivolts (peak-to-peak) or 0-1.5 millivolts (root mean square) and the frequency is from 0- $500 \mathrm{~Hz}$.

\subsection{Signal filtering}

Signal filtering is an important process that removes some unwanted components of features of the signal. The correct filter setting will significantly improve the visibility of a defect signal, incorrect setting of filter will distort the signal presentation then defect the signal completely. Generally, a filter will limit the frequency spectrum of recorded signal which are normally comprised of low frequency component and remove high pass filter. Most of the studies used frequency $1000 \mathrm{~Hz}$ and $2000 \mathrm{~Hz}$ [21]. Table 2 is shows the lists of sampling frequency, type of filter and bandwidth frequencies of previous researches for a few years.

Table 2. Sampling frequency, type of filter and bandwidth

\begin{tabular}{cccc}
\hline References & Types of filter & Sampling frequency, fs (Hz) & Bandwidth (Hz) \\
\hline Karthick et al, [22] & Butterworth filter & 10000 & $10-400$ \\
Amanda et al, [23] & Bandstop filter & 1000 & $0-500$ \\
Gurmanik et al, [24] & Bandpass filter/ low pass & $20 \mathrm{k} / 8000$ & $3000-10 \mathrm{k}$ \\
Edward et al, [25] & Bandpass filter & 4096 & $10-2000$ \\
Wang et al, [26] & Bandpass filter & 1000 & $10-500$ \\
Isa. H et al, [27] & Bandpass filter & 1000 & $85-500$ \\
E. Gokgoz et al, [28] & High and low pass filters & 2000 & $2-10 \mathrm{k}$ \\
E. Shair et al, [29] & Low pass filter & 1500 & $20-500$ \\
L. Estrada et al., [30] & Low pass filter & 2000 & $50-300$ \\
\hline
\end{tabular}

Electromyography (EMG) is the analytical study of electrical activity produced by skeletal muscles [20]. By applying EMG electrodes to capture the data, it is able to provide detailed muscle's information that involve in musculoskeletal disorder, thus, will help SOCSO to identify the exact problem for their patient. The measurement of muscle signal as electromyography (EMG) is able to assist SOCSO for diagnoses MSDs problems.

\section{SURFACE EMG SIGNAL ANALYSIS}

Digital signal processing or signal processing is concerning the extraction of features and information from measured raw signals. It has been used in many applications such as radar, communication and multimedia, medical imaging, speech generation and recognition, and data compression. EMG signal is acquired from the muscles that required advanced methods for detection, decomposition, processing, and classification of the signal [31]. Time-frequency representation has received considerable attention as a powerful high resolution and precision tool for analysing a variety of bio-signals and system such as ECG, EEG and EMG.

There are several parts of signal processing techniques to analyse the EMG signal. EMG signal is one of the biosignal which are the critical part of biomedical engineering to be processed and classify the signal's information [18]. Surface EMG signals can be processed in three domains, which are time domain, frequency domain and time-frequency domain. The differentiation of the signal will decided what type of domain suitable and efficient to use for the signals. The mathematical functions in the time domain and frequency domain are usually used as a dimensionality reduction method for time-frequency domain features [21]. 


\subsection{Time domain features}

Time domain information is obtained from raw signal in time representation. The extraction of features is usually quick and easy to be implemented because it involves simple mathematical properties and do not need any transformation based on raw EMG in time information. In has widely used on both medical and engineering research and practices due to their low computational complexity and the low noise environment, however, this method has the major disadvantage of features EMG signal which comes from non-stationary signal with changing in statistical properties over time, but the time domain assumes the data in stationary signal [21], [32]. Table 3 shows the common extracted features for EMG signal analysis in time domain information.

Table 3. Common features extract of EMG signal in time domain

\begin{tabular}{|c|c|c|}
\hline Features & Function & Mathematical Equation \\
\hline Integrated EMG (IEMG) & 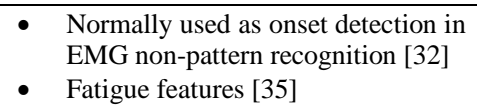 & IEMG $=\sum_{n=1}^{N}\left|X_{n}\right|$ \\
\hline Root Mean Square (RMS) & $\begin{array}{l}\text { - It is modelled as amplitude } \\
\text { modulated Gaussian random } \\
\text { process who is related to content } \\
\text { force and non-fatigue contraction. } \\
\text { - Similar to standard deviation } \\
\text { method [35] } \\
\text { - Fatigue features [21], [36] }\end{array}$ & $\mathrm{RMS}=\sqrt{\frac{1}{N} \sum_{n=1}^{N}\left(X(n)^{2}\right)}$ \\
\hline Mean Absolute Value (MAV) & $\begin{array}{l}\text { - Detection of the surface EMG } \\
\text { signal for the prosthetic limb } \\
\text { control } \\
\text { - } \text { Fatigue features [37] } \\
\text { - Providing energy information }\end{array}$ & MAV $=\frac{1}{N} \sum_{n=1}^{N}|x(n)|$ \\
\hline Zero crossing & $\begin{array}{ll}\text { - } & \text { Measurement of frequency } \\
\text { information of EMG } \\
\text { - } & \text { Fatigue features [38] }\end{array}$ & $\begin{array}{c}\mathrm{ZC}=\sum_{n=1}^{N-1}\left[\operatorname{sgn}\left(X_{n} \times X_{n+1}\right) \cap\left|X_{n}-X_{n+1}\right| \geq \text { threshold }\right] \\
\operatorname{sgn}(X)= \begin{cases}1, \text { if } X \geq \text { threshold } \\
0, & \text { otherwise }\end{cases} \end{array}$ \\
\hline v- Order & $\begin{array}{ll}\text { - Implicitly estimates muscle } \\
\text { contraction force, } \mathrm{m}_{\mathrm{i}}[32] \\
\text { - }\end{array}$ & $\begin{array}{c}X_{n}=\left(\gamma m_{n}^{\alpha}\right) x_{n} \\
\mathrm{~V}=\left(\frac{1}{N} \sum_{n=1}^{N} X_{n}^{v}\right)^{\frac{1}{v}}\end{array}$ \\
\hline Log detector & $\begin{array}{l}\text { Provide an estimate muscle } \\
\text { contraction force [32] } \\
\text { - } \text { Fatigue features [40] }\end{array}$ & $\mathrm{LOG}=e^{\frac{1}{N} \sum_{n=1}^{N} \log \left(\left|X_{n}\right|\right)}$ \\
\hline Waveform Length (WL) & 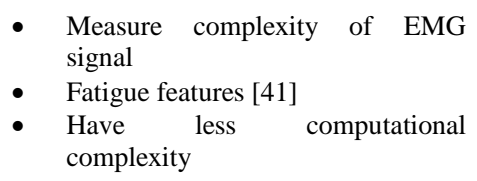 & $\mathrm{WL}=\sum_{n=1}^{N-1}\left|X_{n+1}-X_{n}\right|$ \\
\hline Willison Amplitude (WAMP) & $\begin{array}{ll}\text { - } & \text { Measurement of frequency } \\
\text { information about EMG [32] } \\
\text { - } \text { Fatigue features [42] }\end{array}$ & $\begin{array}{l}\text { WAMP }=\sum_{n=1}^{N-1}\left[f\left(\left|X_{n}-X_{n+1}\right|\right)\right] \\
f(x)=\left\{\begin{array}{l}1, \text { if } n \geq \text { threshold } \\
0, \text { otherwise }\end{array}\right.\end{array}$ \\
\hline Slope sign change (SSC) & $\begin{array}{l}\text { - To represent frequency information } \\
\text { of EMG signal [32] } \\
\text { - One of fatigue features extract } \\
\text { parameters [43] }\end{array}$ & $\begin{aligned} & \mathrm{SSC}= \sum_{n=2}^{N-1}\left[f\left[\left(X_{n}-X_{n-1}\right) \times\left(X_{n}-X_{n-1}\right)\right]\right] \\
& f(x)=\left\{\begin{array}{l}1, \text { if } n \geq \text { threshold } \\
0, \text { otherwise }\end{array}\right.\end{aligned}$ \\
\hline
\end{tabular}

\subsection{Frequency domain features}

The raw signal in time domain should undergo Fourier transform to change from time to frequency domain [46]. Power spectral density (PSD) becomes a major analysis in frequency domain [34]. Most of the signals have to change from time to frequency information for the signal being analysed [35]. Fourier analysis is one of the most widely used tools in signal processing [45], [46]. It is mainly used to extract the characteristic of frequency and good in computation and implementation point of view by permission to get 
the better results [47], [48]. The Fourier transform is represented in terms of the power spectrum and it is defined as [44]:

$$
X(f)=F\{x(t)\}=\int_{-\infty}^{\infty} x(t) e^{-j \pi f t} d t
$$

where $\mathrm{x}(\mathrm{t})$ is the time domain signal, $X(f)$ is the FFT, and $\mathrm{ft}$ is the frequency to analyse. However, there are some of limitation Fourier transform, when have changing in power spectrum that indicate muscle fatigue, the power spectral density (PSD) increases in low component and decreased in high component [21]. Two common and generally features used in PSD is mean frequency (MNF) and median frequency (MDF) to determine muscle fatigue. However, these techniques have the limitation to cater EMG signal behaviour with successfully since it requires a stationary signal for the accurate results [32]. Table 4 indicates the common features proposed in frequency domain information.

Table 4. Common features extract from EMG signal in the frequency domain

\begin{tabular}{|c|c|}
\hline Features & Function \\
\hline Mean Frequency (MNF) & $\begin{array}{l}\text { - It is able to indicate muscle fatigue during } \\
\text { cyclic dynamics [21], [32] } \\
\text { - MNF decrease with increasing force levels } \\
\text { - Universal indices that can detect both } \\
\text { muscle force and muscle fatigue [47], [49] }\end{array}$ \\
\hline Median Frequency (MDF) & $\begin{array}{l}\text { - It is able to indicate muscle fatigue during } \\
\text { cyclic dynamics [21], [32] } \\
\text { - MDF decrease with increasing force levels } \\
\text { - Universal indices that can detect both } \\
\text { muscle force and muscle fatigue [50] } \\
\text { - Fatigue features [51] }\end{array}$ \\
\hline Peak Frequency (PKF) & $\begin{array}{l}\text { - Frequency at which the maximum power } \\
\text { occurs [32] } \\
\text { - Fatigue features [52] }\end{array}$ \\
\hline Mean Power (MNP) & $\begin{array}{l}\text { - Average power of EMG power spectrum } \\
\text { [32] } \\
\text { - } \quad \text { Fatigue features [52] }\end{array}$ \\
\hline Total Power (TTP) & $\begin{array}{l}\text { - Aggregate of the EMG power spectrum } \\
\text { [32] } \\
\text { - } \quad \text { Fatigue features [52] }\end{array}$ \\
\hline $\begin{array}{l}\text { The 1st, 2nd, and 3rd } \\
\text { Spectral moments }\end{array}$ & $\begin{array}{l}\text { - Spectral moment is an alternative statistical } \\
\text { analysis way to extract features from the } \\
\text { EMG power spectrum [32] } \\
\text { - Fatigue features [53] }\end{array}$ \\
\hline Frequency Ratio (FR) & $\begin{array}{l}\text { - Distinguish between contraction and } \\
\text { relaxation (between the low frequency } \\
\text { components and the high frequency } \\
\text { components of) [32] }\end{array}$ \\
\hline
\end{tabular}

Power spectrum ratio (PSR)

Variance of central frequency (VCF)
- $\quad$ Ratio between the energy $\mathrm{P}_{0}$ (nearby the maximum value of EMG power spectrum and the energy $\mathrm{P}$ is the whole energy of the EMG power spectrum [32]

- One of an important characteristic of the PSD [32] Mathematical Equation

$$
\mathrm{MNF}=\frac{\sum_{j=1}^{M} f_{j} P_{j}}{\sum_{j=1}^{M} P_{j}}
$$

$f_{j}$ is frequency of the spectrum at frequency bin $\mathrm{j}, \mathrm{P}_{\mathrm{j}}$ is the EMG power spectrum at frequency bin $\mathrm{j}$, and $\mathrm{M}$ is the length of the frequency bin

$$
\begin{gathered}
\sum_{j=1}^{M D F} P_{j}=\sum_{j=M D F}^{M} P_{j}=\frac{1}{2} \sum_{j=1}^{M} P_{j} \\
\text { spectrum is divided into two } \\
\text { regions with equal amplitude }
\end{gathered}
$$

$$
\mathrm{PKF}=\max \left(P_{j}\right), \mathrm{j}=1, \ldots \ldots, \mathrm{M}
$$

$$
\mathrm{MNP}=\frac{\sum_{\mathrm{j}=1}^{\mathrm{M}} \mathrm{P}_{\mathrm{j}}}{\mathrm{M}}
$$

$\mathrm{TTP}=\sum_{j=1}^{M} P_{j}=S M 0$

where SM0 is zero spectral moment

First three moment- most important spectral moment

$$
\begin{gathered}
\text { SM } 1=\sum_{j=1}^{M} P_{j} f_{j} \\
\text { SM 2 }=\sum_{j=1}^{M} P_{j} f_{j}^{2} \\
\text { SM 3 }=\sum_{j=1}^{M} P_{j} f_{j}^{3}
\end{gathered}
$$

$$
\mathrm{FR}=\frac{\sum_{j=L L C}^{U L C} P_{j}}{\sum_{j=L H C}^{U H C} P_{j}},
$$

ULC and LLC are upper- and lower-cutoff of lo' frequency band

UHC and LHC are upper- and lower-cutoff of hį frequency band

$$
\mathrm{PSR}=\frac{P_{0}}{P}=\frac{\sum_{j=f_{0}-n}^{f_{0}+n} P_{j}}{\sum_{j=-\infty}^{\infty} P_{j}}
$$

$\mathrm{f}_{0}$ is a feature value of the PKF and $\mathrm{n}$ is the integral limit

$\mathrm{VCF}=\frac{1}{S M 0} \sum_{j=1}^{M} P_{j}\left(f_{j}-f_{c}\right)^{2}=\frac{S M 2}{S M 0}-\left(\frac{S M 1}{S M 0}\right)^{2}$ 


\subsection{Time-frequency domain}

In signal processing, time-frequency distributions are powerful and accurate techniques that represent a signal in jointly time and frequency representation [32], [55]. In an analysis of the signals, TFR is widely used in modifying and synthesizing of non-stationary signals because it provides time and frequency information for the signals. For that reason, the time-frequency distributions (TFDs) are appropriate to analyse EMG signals that consist of non-stationary and multi-frequency components signal [32]. TFDs are broadly classified into two categories which are linear and bilinear TFD. Table 5 shows the several of mathematical equation for time-frequency analysis method from linear and bilinear TFD.

Table 5. Time-frequency signal processing method

\begin{tabular}{cc}
\hline Method & $C(n, k)=\int_{-\infty}^{\infty} x(\tau) h *(n, k) d \tau$ \\
Gabor & $S_{x}(t, f)=\left|\int_{-\infty}^{\infty} h(\tau) w(\tau-t) e^{-j 2 \pi f \tau} d \tau\right|^{2}$ \\
Wavelet & $C W T(t, a)=\int_{-\infty}^{\infty} x(\tau) \frac{1}{\sqrt{|a|}} \Psi *\left(\frac{\tau-t}{a}\right) d \tau$ \\
S-Transform & $S(\tau, f)=\int_{-\infty}^{\infty} h(t) \frac{|f|}{\sqrt{2 \pi}} e^{\left.-(\tau-t)^{2} f^{2} / 2\right)} e^{-j 2 \pi f t} d t$ \\
Wigner-Ville distribution (WVD) & $W V D_{x}(t, f)=\frac{1}{2 \pi} \int x\left(t+\frac{\tau}{2}\right) x *\left(t-\frac{\tau}{2}\right) e^{-2 \pi f t} d \tau$ \\
Choi-Williams distribution (CWD) & $C W D_{x}(t, f)=\iint \frac{1}{\sqrt{\frac{4 \pi \tau^{2}}{\sigma}}} e\left(-\frac{(\mu-t)}{\frac{4 \tau^{2}}{\sigma}}\right) x\left(\mu+\frac{\tau}{2}\right) x *\left(\mu+\frac{\tau}{2}\right) e^{-2 \pi f t} d t$
\end{tabular}

\subsubsection{Linear Time-Frequency Dsitribution (TFD)}

Linear TFD is more basic form compared to bilinear TFD. The common techniques used are Gabor, Short-time Fourier Transform (STFT), Spectrogram, wavelet transform (WT) and S-Transform [32].

a) Gabor

Dennis Gabor, a British physicist, suggested expanding a signal into a set of functions that are concentrated in both the time and frequency domains, and then use the coefficients as the description of the signal's local property [56] Gabor transform is defined as:

$$
C(n, k)=\int_{-\infty}^{\infty} x(\tau) h *(n, k) d \tau
$$

where $x(t)$ is the signal under analysis and $h(n, k)$ is the set of elementary function and is defined as:

$$
h(n, k)=w\left(\tau-n T_{w}\right) e^{-j 2 \pi k f_{0} \tau}
$$

where $w(t)$ is the observation window. $T_{w}$ and $f_{0}$ are the time and frequency sampling interval that must satisfy the Heisenberg uncertainty relation [55], [56].

$$
T_{w} f_{0} \geq \frac{1}{4 \pi}
$$

b) Spectrogram

Spectrogram provides a distribution of energy signal in time-frequency distribution (TFR) which is represented in three-dimensional of the signal energy with respect to time and frequency [57]. The optimum frequency is useful for extracting features of any signals for further analysis, including Electromyography (EMG) signals [58]. This technique is roughly reflected how frequency content changes over the time. Smaller size window produces better time resolution, but reduces frequency resolution [59]-[61]. The chosen window width has been maintained and gives fixed frequency and time resolution for all frequencies [44]. 
The equation of spectrogram is as Equation 5.

$$
S_{x}(t, f)=\left|\int_{-\infty}^{\infty} h(\tau) w(\tau-t) e^{-j 2 \pi f \tau} d \tau\right|^{2}
$$

where $h(\tau)$ is the input signal and $w(t)$ is the window observation window. In this study, Hanning window is selected because of its lower peak side slope which is narrow effect to provide higher accuracy on other frequencies around fundamental value and other frequency components.

c) Wavelet Transform (WT)

Wavelet transform (WT) is one of the efficient mathematical tools for local analysis of nonstationary and fast-transient signals. WT is another linear TFD technique that was explored widely in various researches as an alternative to STFT [62]. This method has improved to reveal the information that the signal contains both in time and in frequency to analyse the non-stationary signals [59]. WT functions by shifting and spreading the mother wavelet [63]. The WT offers high time resolution for high frequency component and high frequency resolution for low frequency component such as transient [64], [65]. The estimation provided by WT is better accuracy and precision of simulated data set [32]. However, WT is incapable to give an accurate result under noise condition [66]. This technique successful to use for EMG, but it is not capable to give the information with effectively. This is because EMG signal acquire noise while travelling through different tissue in the human body [31]. But, it is different with continuous wavelet transform (CWT) that able to show better performing in extracting indices in time-frequency domain [32]. In analysis, it's able to give comparable fatigue estimates in isometrics and dynamic contractions.

$$
C W T(t, a)=\int_{-\infty}^{\infty} x(\tau) \frac{1}{\sqrt{|a|}} \Psi *\left(\frac{\tau-t}{a}\right) d \tau
$$

where $t$ is translation, $a$ as scale parameter and $\Psi$ is the mother wavelet.

d) S-transform

S-transform is a TFR that known for its local spectral phase properties where it is an extension ideas of WT and STFT [66]. In S-transform techniques, the frequency-dependent window allows for a frequencydependent resolution with narrower windows at higher frequencies and wider windows at lower frequencies [67]. It uniquely combines a frequency-dependent resolution that simultaneously localizes the real and imaginary spectra.

The S-transform technique was used in many applications such as Geophysics, Biomedical Engineering, power transformer protection, power quality analysis, oceanography, atmospheric physics, medicine, hydrogeology and mechanical engineering [68]. The advantages of S-transform are scalability and very low sensitivity to noise levels [69]. The features extracted from the S-transform are simple and very effective [68], [79]. Moreover, this technique provides multiresolution analysis while retaining the absolute phase of each frequency [68], [71]. In addition, the S-transform has other disadvantages such as its accuracy depends on the chosen size of the windows, sensitivity to noise and it requires higher complexity computation [72]. The mathematical formula for S-Transform is expressed as follows:

$$
S(\tau, f)=\int_{-\infty}^{\infty} h(t) \frac{|f|}{\sqrt{2 \pi}} e^{\left.-(\tau-t)^{2} f^{2} / 2\right)} e^{-j 2 \pi f t} d t
$$

where $\mathrm{h}(\mathrm{t})$ is the signal and $\mathrm{g}(\tau)$ is a window function. Windows function is a modulated Gaussian function expressed by:

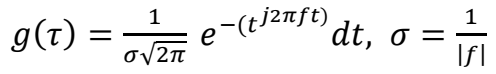

\subsubsection{Bilinear Time-Frequency Dsitribution (TFD)}

Unlike linear time-frequency transforms, the signal appears twice in bilinear time-frequency transforms, so called bilinear transform. Bilinear TFD could perform better than the linear TFD due to the fact that it does not suffer for the smearing effects cause by windowing function. However, bilinear TFD suffers the cross term effects or artifacts which present in the midway between the actual frequency components of multicomponent signals [22], [73]. Wigner-Ville distribution (WVD), and Choi-Williams distribution (CWD) are some of the time-frequency approaches from bilinear TFD that is used for EMG signal processing [31]. That is the reason this paper is the focus of this type's of bilinear method 
a) Wigner-Ville distribution (WVD)

Wigner-Ville distribution (WVD) has attracted much attention from other bilinear TFD because of its several desirable mathematical properties such as preserving time and frequency marginals and shifts. It offers a high frequency resolution, but still creates spurious frequency information or cross-terms interferences when it is applied to multi-component signals [74]. The joint density spectrum produced by WVD able to display very good localization properties. It generally concentrated around the instantaneous frequency of the signal, but it is very noisy [31]. Furthermore, it also has the disadvantage which is not a precise representation of the changing of frequency components with fatigue. Equation (9) shows the formula for WVD as follows.

$$
W V D_{x}(t, f)=\frac{1}{2 \pi} \int x\left(t+\frac{\tau}{2}\right) x *\left(t-\frac{\tau}{2}\right) e^{-2 \pi f t} d \tau
$$

where $\int x\left(t+\frac{\tau}{2}\right) x *\left(t-\frac{\tau}{2}\right)$ is the instantaneous autocorrelation function and $*$ is the conjugate operation.

b) Choi-Williams distribution (CWD)

Choi-Williams distribution (CWD) is time-frequency spectrum of a discrete time signal which is sampled at sampling frequency that can obtained by the square modulus of its short-time Fourier transform with the time window [76], [77]. This technique is able to avoid one of the main problems of WVD which is reducing interference [18] and it is said as the most accurately show the frequency compression [74]. CWD does not suffer from this problem, but it creates lower resolution and an increase in the computational resources [78]. Besides that, it is not satisfying all the desired properties for a time frequency distribution [31]. The formula for CWD is definitely as Equation (10).

$$
C W D_{x}(t, f)=\iint \frac{1}{\sqrt{\frac{4 \pi \tau^{2}}{\sigma}}} e\left(-\frac{(\mu-t)}{\frac{4 \tau^{2}}{\sigma}}\right) x\left(\mu+\frac{\tau}{2}\right) x *\left(\mu+\frac{\tau}{2}\right) e^{-2 \pi f t} d t
$$

where $x$ is the input signal value, $x *$ is the complex conjugate of $x$.

\section{CONCLUSION}

The review of the relation function of EMG on musculoskeletal disorder (MSDs) is shown and the used of surface EMG to access the features and characteristic of the signal was reviewed. The purpose of this paper is to provide the details of information of surface Electromyography for the analysis of MSDs on the methodologies used for detecting and processing the EMG signal. In an analysis of EMG signals, one of the most important processes is to extract the suitable features that will affect the developed application of the chosen technique. There are some other techniques have been used in the analysis, however, the common techniques of analysis is selected to be explored and the features of time domain, frequency domain and timefrequency domain have been extracted from the analysis of EMG signal in order to diagnose and localise the exact problem of the muscles that will contribute to MSDs problems.

\section{ACKNOWLEDGEMENT}

This work is superficially wanted to appreciate the Minister of Higher Education (MOHE), Universiti Teknikal Malaysia Melaka and UTeM Zamalah Scheme, Faculty of Electrical Engineering of Universiti Teknikal Malaysia Melaka (UTeM) for funding research work under grant PJP/2017/FKEKK/HI9/S01526. We would also want to extend our gratitude to all team members for this paper from part of Advanced Digital Signal Processing Group (ADSP) from the Centre of Robotic \& Industrial Information (CeRIA), for their contribution and suggestion to successfully complete this paper.

\section{REFERENCES}

[1] Daneshmandi, Hadi, A. R. Choobineh, Haleh Ghaem, Mehdi Alhamd, and Anahita Fakherpour. The effect of musculoskeletal problems on fatigue and productivity of office personnel: a cross-sectional study. Journal of preventive medicine and hygiene. 2017; 58(3): 252.

[2] Murad MS, Farnworth L, O'Brien L. Reliability and validation properties of the Malaysian language version of the Occupational Self Assessment version 2.2 for injured workers with musculoskeletal disorders. British Journal of Occupational Therapy. May 2011; 74(5): 226-232. 
[3] Matt, M. The Definition and Causes of Musculoskeletal Disorder. Ergo-plus. Available at: http://ergoplus.com/musculoskeletal-disorders-msd/ [Accessed on 13 April 2018]

[4] Salvendy G. Handbook of human factors and ergonomics. John Wiley \& Sons; 2012 May 24.

[5] Buckle P. Ergonomics and musculoskeletal disorders: overview. Occupational medicine. 1 May 2005; 55(3): 164167.

[6] Armijo-Olivo, Susan, Linda J. Woodhouse, Ivan A. Steenstra, and Douglas P. Gross. Predictive value of the DASH tool for predicting return to work of injured workers with musculoskeletal disorders of the upper extremity. Occup Environ Med. 2016; 73(12): 807-815.

[7] Starovoytova, D. Hazards and Risks at Rotary Screen Printing ( Part 2 / 6 ): Analysis of Machine-operators' Posture via Rapid-Upper-Limb-Assessment (RULA). Industrial Engineering Letters. 2017; 7(5): 42-63.

[8] Abas AB, Said AR, Mohammed MA, Sathiakumar N. Occupational disease among non-governmental employees in Malaysia: 2002-2006. International journal of occupational and environmental health. 2008 Oct 1; 14(4): 26371.

[9] Hui-Nee AU. Safety Culture in Malaysian Workplace: An Analysis of Occupational Accidents. Health and the Environment Journal. 2014; 5(3): 32-43.

[10] Buckley P. Work-related Musculoskeletal Disorder (WRMSDs) statistics. Health and Safety Executive, Great Britain. 2016:1-20.

[11] Nazmi N, Abdul Rahman MA, Yamamoto SI, Ahmad SA, Zamzuri H, Mazlan SA. A review of classification techniques of EMG signals during isotonic and isometric contractions. Sensors. 2016 Aug 17; 16(8):1304.

[12] Zurada J. Predicting the Risk of Low Back Disorders due to Manual Handling Tasks. InSystem Science (HICSS), 2012 45th Hawaii International Conference on 2012 Jan 4 (pp. 1080-1088). IEEE.

[13] Das SK, Mukhopadhyay S. Effect of altered body composition on musculoskeletal disorders in medical practitioners. International Journal of Research in Engineering and Technology. 2016; 5(16):1-6.

[14] Hashim N, Kamat SR, Halim I, Othman MS. A study on push-pull analysis associated with awkward posture among workers in aerospace industry. International Journal of Research in Engineering and Technology. 2014; 3(1); 233-239.

[15] Ghosh T. Assessment of Postural effect on Work Related Musculoskeletal Disorders and Back Muscle Fatigue among the Goldsmiths of India. International Journal of Occupational Safety and Health. 2017 Aug 6; 5(2):16-22.

[16] Nur NM, Dawal SZ. Upper limb and lower back muscle activity during prolonged sitting. InScience and Technology for Humanity (TIC-STH), 2009 IEEE Toronto International Conference 2009 Sep 26 (pp. 234-238). IEEE.

[17] Nur NM, Dawal SZ. Muscles activities at two different work area boundaries during sedentary work. InBiomedical Engineering and Sciences (IECBES), 2010 IEEE EMBS Conference on 2010 Nov 30 (pp. 369-372). IEEE.

[18] Shair EF, Ahmad SA, Marhaban MH, Mohd Tamrin SB, Abdullah AR. EMG Processing Based Measures of Fatigue Assessment during Manual Lifting. BioMed research international. 2017; 2017: 1-12.

[19] Rafie F, Zamani Jam A, Shahravan A, Raoof M, Eskandarizadeh A. Prevalence of upper extremity musculoskeletal disorders in dentists: symptoms and risk factors. Journal of environmental and public health. 2015; 2015: 1-6.

[20] Ruchika SD. An explanatory study of the parameters to be measured from EMG signal. International Journal of Engineering and Computer Science. 2013 Jan; 2(1):207-213.

[21] Kamaruddin NA, Khalid PI, Shaameri AZ. The Use of Surface Electromyography in Muscle Fatigue AssessmentsA Review. Jurnal Teknologi. 2015 Jan 1; 74(6):119-24.

[22] Karthick PA, Ramakrishnan S. Surface electromyography based muscle fatigue progression analysis using modified B distribution time-frequency features. Biomedical Signal Processing and Control. 2016 Apr 1; 26:42-51.

[23] Nebel, Amanda, and James E. Whitney ii. Signal Processing for Electromyography Parameter Estimation. Mathematics and Computers in Biology and Biomedical Informatics. pp.37-44

[24] Kaur G, Arora AS, Jain VK. Comparison of the techniques used for segmentation of EMG signals. In Proceedings of the 11th WSEAS international conference on Mathematical and computational methods in science and engineering. World Scientific and Engineering Academy and Society (WSEAS). 2009 Nov 7; 124-129.

[25] Clancy EA, Liu L, Liu P, Moyer DV. Identification of constant-posture EMG-torque relationship about the elbow using nonlinear dynamic models. IEEE Transactions on Biomedical Engineering. 2012 Jan; 59(1):205-212.

[26] Wang G, Yan Z, Hu X, Xie H, Wang Z. Classification of surface EMG signals using harmonic wavelet packet transform. Physiological measurement. 2006 Oct 10; 27(12):1255-1267.

[27] Halim I, Omar AR, Saman AM, Othman I. Assessment of muscle fatigue associated with prolonged standing in the workplace. Safety and health at work. 2012 Mar 1; 3(1):31-42.

[28] Gokgoz E, Subasi A. Comparison of decision tree algorithms for EMG signal classification using DWT. Biomedical Signal Processing and Control. 2015 Apr 1; 18: 138-44.

[29] Estrada L, Torres A, Garcia-Casado J, Sarlabous L, Prats-Boluda G, Jané R. Time-frequency representations of the sternocleidomastoid muscle electromyographic signal recorded with concentric ring electrodes. In 2016 IEEE 38th Annual International Conference of the Engineering in Medicine and Biology Society (EMBC), 2016 Aug 16: pp. 3785-3788. IEEE.

[30] Shair EF, Zawawi TN, Abdullah AR, Shamsudin NH, Halim I. sEMG signals analysis using time-frequency distribution for symmetric and asymmetric lifting. In 2015 International Symposium on Technology Management and Emerging Technologies (ISTMET), 2015 Aug 25: pp. 233-237. IEEE.

[31] Reaz MB, Hussain MS, Mohd-Yasin F. Techniques of EMG signal analysis: detection, processing, classification and applications. Biological procedures online. 2006 Dec 1; 8(1):11-35. 
[32] Phinyomark A, Phukpattaranont P, Limsakul C. Feature reduction and selection for EMG signal classification. Expert Systems with Applications. 2012 Jun 15; 39 (8):7420-31.

[33] Abidullah NA, Abdullah AR, Shamsudin NH, Ahmad NH, Jopri MH. Real-time power quality signals monitoring system. In Research and Development (SCOReD), 2013 IEEE Student Conference on 2013 Dec 16: 433-438. IEEE.

[34] Abidullah NA, Abdullah AR, Sha'ameri AZ, Shamsudin NH, Ahmad NH, Jopri MH. Real-Time Power Quality Disturbances Detection and Classification System. World Applied Sciences Journal. 2014;32(8):1637-51.

[35] Malinzak RA, Colby SM, Kirkendall DT, Yu B, Garrett WE. A comparison of knee joint motion patterns between men and women in selected athletic tasks. Clinical biomechanics. 2001 Jun 1; 16 (5):438-45.

[36] Arabadzhiev TI, Dimitrov VG, Dimitrova NA, Dimitrov GV. Interpretation of EMG integral or RMS and estimates of "neuromuscular efficiency" can be misleading in fatiguing contraction. Journal of Electromyography and Kinesiology. 2010 Apr 1; 20(2): 223-32.

[37] Suetta C, Aagaard P, Rosted A, Jakobsen AK, Duus B, Kjaer M, Magnusson SP. Training-induced changes in muscle CSA, muscle strength, EMG, and rate of force development in elderly subjects after long-term unilateral disuse. Journal of Applied Physiology. 2004 Nov; 97(5):1954-61.

[38] Kilbom Å, Hägg GM, Käll C. One-handed load carrying-cardiovascular, muscular and subjective indices of endurance and fatigue. European journal of applied physiology and occupational physiology. 1992 Jan 1; 65(1):528.

[39] Tkach D, Huang H, Kuiken TA. Study of stability of time-domain features for electromyographic pattern recognition. Journal of neuroengineering and rehabilitation. 2010 Dec; 7(21): 1-13.

[40] Zardoshti-Kermani M, Wheeler BC, Badie K, Hashemi RM. EMG feature evaluation for movement control of upper extremity prostheses. IEEE Transactions on Rehabilitation Engineering. 1995 Dec;3(4):324-33.

[41] Kiguchi K, Kariya S, Watanabe K, Izumi K, Fukuda T. An exoskeletal robot for human elbow motion supportsensor fusion, adaptation, and control. IEEE Transactions on Systems, Man, and Cybernetics, Part B (Cybernetics). 2001 Jun; 31(3):353-361.

[42] Phinyomark A, Chujit G, Phukpattaranont P, Limsakul C, Hu H. A preliminary study assessing time-domain EMG features of classifying exercises in preventing falls in the elderly. In 2012 9th International Conference on Electrical Engineering/Electronics, Computer, Telecommunications and Information Technology (ECTI-CON), 2012 May 16: pp. 1-4. IEEE.

[43] Rogers DR, MacIsaac DT. EMG-based muscle fatigue assessment during dynamic contractions using principal component analysis. Journal of Electromyography and Kinesiology. 2011 Oct 1; 21(5):811-818.

[44] Abidin NZ, Abdullah AR, Norddin N, Aman A, Ibrahim KA. Leakage current analysis on polymeric surface condition using time-frequency distribution. 2012 IEEE International in Power Engineering and Optimization Conference (PEOCO) Melaka, Malaysia, 2012 Jun 6: pp. 171-175. IEEE.

[45] Saxena R, Singh K. Fractional Fourier transform: A novel tool for signal processing. Journal of the Indian Institute of Science. 2013 Jul 5; 85(1):11.

[46] Kay SM. Fundamentals of statistical signal processing: Practical algorithm development. Pearson Education; 2013.

[47] Bekka RE, Chikouche D. Effect of the window length on the EMG spectral estimation through the Blackman-Tukey method. In Signal Processing and Its Applications, 2003. Proceedings. Seventh International Symposium on 2003 Jul 1; 2: 17-20. IEEE.

[48] Jopri MH, Abdullah AR, Kassim NM, Manap M, Ngatiman NA, Yusoff MR. Localization of Multiple Harmonic Sources for Inverter Loads Utilizing Periodogram. Journal of Telecommunication, Electronic and Computer Engineering (JTEC). 2016 May 1;8(2):87-91.

[49] Thongpanja S, Phinyomark A, Phukpattaranont P, Limsakul C. Mean and median frequency of EMG signal to determine muscle force based on time-dependent power spectrum. Elektronika ir Elektrotechnika. 2013 Jul; 19(3):51-56.

[50] Merletti R, Conte LR. Surface EMG signal processing during isometric contractions. Journal of Electromyography and Kinesiology. 1997 Dec 1;7(4):241-50.

[51] De Luca CJ. Use of the surface EMG signal for performance evaluation of back muscles. Muscle \& nerve. 1993 Feb 1; 16(2):210-216.

[52] Khanam F, Ahmad M. Frequency based EMG power spectrum analysis of Salat associated muscle contraction. In 2015 International Conference on Electrical \& Electronic Engineering (ICEEE), 2015 Nov 4: pp. 161-164. IEEE.

[53] Altaf MM, Elbagoury BM, Alraddady F, Roushdy M. Extended case-based behavior control for multi-humanoid robots. International Journal of Humanoid Robotics. 2016 Jun; 13(02):1550035-1- 1550035-18.

[54] Wacker M, Witte H. Time-frequency techniques in biomedical signal analysis. Methods of information in medicine. 2013; 52(4):279-96.

[55] Yuan L. A Time-Frequency Feature Fusion Algorithm Based on Neural Network for HRRP. Progress in Electromagnetics Research. 2017; 55:63-71.

[56] Jopri MH, Abdullah AR, Sutikno T, Manap M, Yusoff MR. A Utilisation of Improved Gabor Transform for Harmonic Signals Detection and Classification Analysis. International Journal of Electrical and Computer Engineering (IJECE). 2017 Feb 1; 7(1):21-8.

[57] Abdullah AR, Ahmad NS, Bahari N, Manap M, Jidin A, Jopri MH. Short-circuit switches fault analysis of voltage source inverter using spectrogram. In Electrical Machines and Systems (ICEMS), 2013 International Conference on 2013 Oct 26 (pp. 1808-1813). IEEE.

[58] Plante F, Meyer G, Ainsworth WA. Improvement of speech spectrogram accuracy by the method of reassignment. 
IEEE Transactions on Speech and Audio Processing. 1998 May; 6(3):282-7.

[59] Kilby J, Prasad K. Analysis of surface electromyography signals using discrete Fourier transform sliding window technique. International Journal of Computer Theory and Engineering. 2013 Apr 1; 5(2):321.

[60] Abdullah AR, Abidullah NA, Shamsudin NH, Ahmad NH, Jopri MH. Performance Verification of Power Quality Signals Classification System. In Applied Mechanics and Materials 2015; 752: pp. 1158-1163. Trans Tech Publications.

[61] Abdullah AR, Abidullah NA, Shamsudin NH, Ahmad NH, Jopri MH. Power Quality Signals Classification System Using Time-Frequency Distribution. In Applied Mechanics and Materials 2014; 494: 1889-1894. Trans Tech Publications.

[62] Jopri MH, Abidullah NA, Peng GZ, Abdullah AR. A new two points method for identify dominant harmonic disturbance using frequency and phase spectrogram. Int. Rev. Electr. Eng. 2014;9(2):453-9.

[63] Bigliassi M, Scalassara PR, Kanthack TF, Abrão T, de Moraes AC, Altimari LR. Fourier and Wavelet Spectral Analysis of EMG Signals in 1-km Cycling Time-Trial. Applied Mathematics. 2014 Jul 7; 5(13):1878.

[64] Canal MR. Comparison of wavelet and short time Fourier transform methods in the analysis of EMG signals. Journal of medical systems. 2010 Feb 1; 34(1):91-4.

[65] Andreotti A, Bracale A, Caramia P, Carpinelli G. Adaptive prony method for the calculation of power-quality indices in the presence of nonstationary disturbance waveforms. IEEE Transactions on Power Delivery. 2009 Apr; 24(2):874-83.

[66] Basir MS, Abdullah AR, Selamat NA, Musa H, Ranom R. Lead Acid Battery Analysis using S-Transform. International Journal on Advanced Science, Engineering and Information Technology. 2017 Oct 31; 7(5):1832-9.

[67] Abdullah AR, Ahmad NH, Abidullah NA, Shamsudin NH, Jopri MH. Performance Evaluation of Real Power Quality Disturbances Analysis using S-transform. Applied Mechanics \& Materials. 2015 Apr 18;752: 1343-1348.

[68] Dora C, Biswal PK. Robust ECG artifact removal from EEG using continuous wavelet transformation and linear regression. In Signal Processing and Communications (SPCOM), 2016 International Conference on 2016 Jun 12: 1-5. IEEE.

[69] Huda NH, Abdullah AR, Jopri MH. Power quality signals detection using S-transform. 2013 IEEE 7th International in Power Engineering and Optimization Conference (PEOCO), 2013 Jun 3: 552-557. IEEE.

[70] Sahu SS, Panda G, George NV. An improved S-transform for time-frequency analysis. IEEE International 2009 in Advance Computing Conference, 2009. IACC 2009. Mar 6: 315-319. IEEE.

[71] Uyar M, Yildirim S, Gencoglu MT. An expert system based on S-transform and neural network for automatic classification of power quality disturbances. Expert Systems with Applications. 2009 Apr 1; 36(3):5962-5975.

[72] Jopri MH, Abdullah AR, Manap M, Habban MF, Sutikno T. An Accurate Classification Method of Harmonic Signals in Power Distribution System by Utilising S-Transform. Telkomnika. 2017 Mar 1;15(1).

[73] Lee IW, Dash PK. S-transform-based intelligent system for classification of power quality disturbance signals. IEEE Transactions on Industrial Electronics. 2003 Aug; 50(4):800-805.

[74] Ricamato AL, Absher RG, Moffroid MT, Tranowski JP. A time-frequency approach to evaluate electromyographic recordings. Fifth Annual IEEE Symposium Proceedings in Computer-Based Medical Systems 1992, on 1992 Jun 14: 520-527. IEEE.

[75] Feltane A. Time-frequency based methods for nonstationary signal analysis with application to EEG signals. University of Rhode Island; 2016.

[76] Norali AN, Som MM, Kangar-arau J. Surface electromyography signal processing and application: A review. InProceedings of the International Conference on Man-Machine Systems (ICoMMS) 2009 Oct: 11-13.

[77] Xu LQ, Hu LQ, Chen KY, Li EZ. Time-frequency analysis of nonstationary complex magneto-hydro-dynamics in fusion plasma signals using the Choi-Williams distribution. Fusion Engineering and Design. 2013 Nov 1; 88(11):2767-72.

[78] Abdullah AR, Sha'ameri AZ, Jidin AB. Classification of power quality signals using smooth-windowed WignerVille distribution. In Electrical Machines and Systems (ICEMS), 2010 International Conference on 2010 Oct 10: 1981-1985. IEEE.

[79] Habban MF, Manap M, Abdullah AR, Jopri MH, Sutikno T. An Evaluation of linear time frequency distribution Analysis for VSI switch faults identification. International Journal of Power Electronics and Drive Systems (IJPEDS). 2017 Mar 1;8(1):1-9. 